\title{
REGIONAL AND ETHNIC ASPECTS OF VIRAL HEPATITIS B AMONG PREGNANT WOMEN
}

\author{
Pavol Kristian', Zuzana Dankulincová Veselská², Zuzana Paraličová1, PeterJarčuška, Ladislav Virág1, Ivana \\ Valková', Ivan Schréter ${ }^{1}$ \\ 1Department of Infectology and Travel Medicine, Medical Faculty, PJ Šafárik University, Košice, Slovak Republic \\ ${ }^{2}$ Health Psychology Unit, Institute of Public Health, Medical Faculty, PJ Šafárik University, Košice, Slovak Republic \\ ${ }^{3} 1$ st Department of Internal Medicine, Medical Faculty, PJ Šafárik University, Košice, Slovak Republic
}

\begin{abstract}
SUMMARY
Objectives: The aim of this study was to determine the prevalence of HBV infection among pregnant women in districts of Eastern Slovakia with a diverse prevalence of Roma population.

Methods: Overall 59,279 serum samples from 9 regional departments of clinical microbiology from Eastern Slovakia were collected in the period from January 2008 till December 2009 and analysed.

Results: The number of HBsAg positive samples overall and during pregnancy was $1.74 \%$ and $2.12 \%$, respectively. Comparing districts with higher $(>5 \%)$ and lower $(<5 \%)$ Roma population, there was no significant difference in the prevalence of HBsAg positive samples overall $(1.95 \%$ vs.1.62\%). However, in the subgroup of pregnant women the prevalence of HBsAg positive samples (2.72\% vs. $0.95 \%)$ differs significantly ( $p<0.01$ ).

Conclusions: The prevalence of HBV infection among pregnant women in Eastern Slovakia did not rapidly exceed the estimated nationwide prevalence. However, in districts with higher Roma population the expected higher prevalence of HBV infection was confirmed. This indicates the need to pay special attention to the prevention of hepatitis $B$ in these districts.
\end{abstract}

Key words: hepatitis B, pregnancy, regional differences, ethnicity

Address for correspondence: Z. Dankulincová Veselská, Health Psychology Unit, Institute of Public Health, Medical Faculty, PJ Šafárik University, Tr. SNP 1, 04066 Košice, Slovakia. E-mail: zuzana.veselska@upjs.sk

\section{INTRODUCTION}

Worldwide, about 350 million people are chronically infected with hepatitis B virus (HBV), and about one million deaths per year have been reported due to chronic hepatitis, cirrhosis and hepatocellular carcinoma $(1,2)$. With regard to HBV, pregnant women are a specific target group due to the risk of vertical transmission of the infection, which occurs usually in the perinatal period and is the major cause of HBV transmission, particularly in countries of the world where HBV has intermediate to high prevalence. Mother-to-infant transmission represents a basic factor in maintaining chronic HBV infection and usually depends on the degree of maternal infectivity, especially in the perinatal period (3). It has long been recognised that prevention of perinatal transmission is a high priority in the attempt to decrease the global burden of chronic HBV (4). Pregnant women constitute a special subgroup which is subject to routine HBsAg screening because of the risk of vertical transmission. At the same time, pregnancy can modify the course of hepatitis B infection $(5,6)$.

The prevalence of chronic HBV infection varies widely, with rates ranging $0.1-20 \%$ in different parts of the world. European countries have either intermediate (2-8\% HBsAg positive) prevalence (Eastern and Southern Europe) or low (less than 2\% HBsAg positive) prevalence (Northern, Western, and Central Europe) (1). The prevalence of HBsAg positivity among pregnant women varies across the countries of Europe, ranging from less than $0.01 \%$ in North-West Europe to $1-4 \%$ in Southern Europe
(7). However, in these areas, prevalence may vary with race and ethnicity (8). The prevalence of HBsAg positivity in Slovakia is expected to be less than $2 \%$ and at the same time, regional and ethnic differences are expected (9), though they have never been explored and might also be a matter of high interest for other countries in Europe.

In regard to possible ethnic differences in the prevalence of HBsAg positivity, it is important to mention the existing minorities in Slovakia. Based on information from the Statistical Office of the Slovak Republic, there are several minorities living in Slovakia, with two of them predominating. Both the Hungarian and Roma minorities represent $5 \%$ of the population of Eastern Slovakia, where our data were collected. Other minorities living in Eastern Slovakia total less than $1 \%$. The Hungarian minority is fully integrated into the majority population, in contrast to Roma minority, which frequently lives in separated or segregated settlements in very poor conditions, has low educational status, high unemployment and poverty, and might have worse access to health services $(10,11)$. All of these factors might contribute to worse health not only in general but also in the prevalence of specific diseases in an extra-vulnerable target groups like pregnant women with the risk of vertical transmission during pregnancy. At the same time, this minority has been only scarcely studied previously, and the prevalence of $\mathrm{HBV}$ infection among pregnant women in districts with different Roma minority population is unknown.

Therefore, the main aim of this study was to determine the prevalence of HBV infection in pregnant women in districts of 
Eastern Slovakia with a diverse prevalence of the Roma minority population.

\section{MATERIALS AND METHODS}

\section{Sample and Procedure}

A total of 59,279 serum samples from 9 regional departments of clinical microbiology from Eastern Slovakia were collected in the period from January 2008 till December 2009 and analysed. HBsAg was detected (Enzygnost HBsAg 5.0, Siemens Healthcare Diagnostics Products $\mathrm{GmbH}$ ) and the portion of HBsAg positive findings from the overall examined sample and among pregnant women was evaluated.

\section{Statistical Analysis}

Data were analysed with SPSS version 16.0. In the first step, basic descriptive statistics for every district were calculated to determine prevalence rates of chronic hepatitis B in the overall population and in the subgroup of pregnant women. In the next step, the odds ratio and Chi-square test were computed to compare the prevalence of HBsAg positive samples in districts with a lower and higher representation of Roma population.

\section{RESULTS}

Overall 59,279 serum samples were examined and 13,798 of them were part of the pregnancy screening. The number of HBsAg positive samples overall in the whole examined sample and HBsAg positive samples among pregnant women was 1,031 $(1.74 \%)$ and $292(2.12 \%)$, respectively. Table 1 provides information about the total amount of serums examined, the number of HBsAg positive samples overall in the whole examined sample, the total number of pregnant women and the number of HBsAg positive samples among pregnant women separately for 9 regions of Eastern Slovakia and for Eastern Slovakia altogether.

In the second step, based on information from the Statistical Office of the Slovak Republic, which reported the representation of Roma minority population in Eastern Slovakia to be $4.86 \%$, 9 districts were divided into subgroups of regions with a higher and lower than average representation of Roma population, with the cut-off point at $5 \%$. Table 2 provides information about the total amount of serums examined, the number of HBsAg positive samples overall, the total amount of pregnant women and the number of HBsAg positive samples among pregnant women for these two subgroups. The prevalence of HBsAg positive samples overall was similar in these two subgroups of districts $(1.95 \%$ in districts with a higher representation of Roma population vs. $1.62 \%$ in districts with a lower representation of Roma popula-

Table 1. Prevalence of HBsAg positive samples overall $(n, \%)$ and HBsAg positive samples during pregnancy (n, \%) in 9 regions of Eastern Slovakia

\begin{tabular}{|c|c|c|c|c|c|c|c|}
\hline \multirow{2}{*}{ Region } & \multirow{2}{*}{$\begin{array}{c}\text { Roma } \\
\text { population (\%) }\end{array}$} & \multirow{2}{*}{$\begin{array}{l}\text { Examined } \\
\text { samples }\end{array}$} & \multicolumn{2}{|c|}{ HBsAg positive } & \multirow{2}{*}{$\begin{array}{l}\text { Pregnant } \\
\text { women }\end{array}$} & \multicolumn{2}{|c|}{ HBsAg positive pregnant women } \\
\hline & & & $\mathrm{n}$ & $\%$ & & $\mathrm{n}$ & $\%$ \\
\hline Region 1 & 2.18 & 3,667 & 115 & 3.14 & 732 & 6 & 0.82 \\
\hline Region 2 & 2.51 & 16,010 & 248 & 1.55 & 2,186 & 28 & 1.28 \\
\hline Region 3 & 2.66 & 3,032 & 14 & 0.46 & 630 & 4 & 0.63 \\
\hline Region 4 & 4.74 & 2,977 & 40 & 1.34 & 1,227 & 9 & 0.73 \\
\hline Region 5 & 5.32 & 7,691 & 79 & 1.03 & 1,532 & 32 & 2.09 \\
\hline Region 6 & 6.36 & 5,390 & 82 & 1.52 & 627 & 17 & 2.71 \\
\hline Region 7 & 6.68 & 5,416 & 178 & 3.29 & 2,288 & 68 & 2.97 \\
\hline Region 8 & 6.78 & 9,651 & 67 & 0.69 & 1,575 & 4 & 0.25 \\
\hline Region 9 & 7.07 & 5,445 & 208 & 3.82 & 3,001 & 124 & 4.13 \\
\hline Total sample & 4.86 & 59,279 & 1,031 & 1.74 & 1,798 & 292 & 2.12 \\
\hline
\end{tabular}

Table 2. Difference in prevalence of HBsAg overall positive samples ( $n$, \%) and HBsAg positive samples during pregnancy $(n, \%)$ between regions with lower and higher representation of Roma minority population

\begin{tabular}{|c|c|c|c|c|c|}
\hline & \multicolumn{2}{|c|}{$\begin{array}{l}\text { Regions with lower representation } \\
\text { of Roma population }(<5 \%)\end{array}$} & \multicolumn{2}{|c|}{$\begin{array}{l}\text { Regions with higher representation } \\
\text { of Roma population ( } \geq 5 \%)\end{array}$} & \multirow[t]{2}{*}{ Chi-square } \\
\hline & $\mathrm{n}$ & $\%$ & $\mathrm{n}$ & $\%$ & \\
\hline Examined samples & 25,686 & 100 & 33,593 & 100 & \\
\hline HBsAg positive & 417 & 1.62 & 654 & 1.83 & ns \\
\hline Pregnant women & 4,775 & 100 & 9,023 & 100 & \\
\hline HBsAg positive pregnant women & 47 & 0.98 & 245 & 2.72 & $p<0.01$ \\
\hline
\end{tabular}

ns - not significant 
tion). The Chi-square test did not show any significant difference in the prevalence of HBsAg between districts with a lower and higher representation of Roma population $(p>0.05)$. On the other hand, the prevalence of HBsAg positive samples among pregnant women differs between these two subgroups $(2.72 \%$ in districts with a higher representation of Roma population vs. $0.95 \%$ in districts with a lower representation of Roma population). The Chi-square test confirmed the significant difference between the districts with a lower and higher representation of Roma population $(\mathrm{p}<0.01)$, with the prevalence of HBsAg positive samples being higher in districts with a higher representation of Roma population.

\section{DISCUSSION}

The main aim of this study was to determine the prevalence of HBV infection among pregnant women in districts of Eastern Slovakia with a diverse prevalence of Roma minority population. Our findings indicate a significantly higher prevalence of HBsAg positive samples among pregnant women in districts with a higher representation of Roma population, which suggests differences between the Roma and non-Roma populations in Slovakia.

The prevalence of HBV infection in pregnant women in different countries depends on the overall situation in the geographical area. In European countries, the prevalence of HBV ranges from $<0.1 \%$ in North-West Europe to $1-4 \%$ in Southern Europe (8). Even within a single country there might be significant differences between ethnic groups. An example can be seen in the prevalence of HBV found in Greece ( $0.29 \%$ among Greek women compared to $5.1 \%$ prevalence among Albanian minority) in a study by Greek authors (12). A similar pattern was also described in a study conducted in Hungary (13).

Based on our results, similar patterns with possible differences between the majority population and the Roma minority might be seen in Slovakia. These findings might be of high importance, as this ethnic group has scarcely been studied before, they are also in line with two other studies on pregnant Spanish women from the Roma minority with a higher prevalence of HBV infection $(14,15)$. At the same time, it is important to identify pregnant women in this minority as a vulnerable target group because of their possible risk of vertical transmission from mother to child.

In chronic HBV infection, the risk of vertical transmission from mother to child depends on ongoing virus replication (viremia levels). The vertical transmission of HBV infection occurs mostly in cases where maternal viremia is high (8). In some countries, passive immunisation is administered only in cases where the mother is, in addition to HBsAg positive, also HBeAg positive and in whom increased ALT activity has also been found, although the reliability of the latter parameter is questionable (16). Most HBsAg positive pregnant women have a chronic infection that occurs as the so-called asymptomatic HBsAg carrier state with a good prognosis. However, there are known conditions, mostly associated with weakened immune system of the patient, when carrying the virus can lead to the exacerbation of the disease and eventually to chronic active infection (17).

The present study provides information about the prevalence of chronic hepapatis B among pregnant women and at the same time suggests the possible existence of ethnic differences in the prevalence of HBV among pregnant women. Studies on HBV during pregnancy are scarce and the influence of ethnicity has not been fully explored in this region. However, we are aware of possible limitations. More detailed information should be collected in the future studies in order to obtain a more in-depth look at the possible determinants of the prevalence of HBV.

\section{CONCLUSION}

The prevalence of HBV infection among pregnant women in Eastern Slovakia did not rapidly exceed the estimated nationwide prevalence. However, in the districts with a higher representation of Roma population the expected higher prevalence of HBV infection in this population group was confirmed. This indicates the need to pay special attention to the prevention of hepatitis B in these districts.

\section{Acknowledgements}

This work was supported by VEGA under contract No. 1/0050/08.

\section{Ethical Recommendations}

Ethical recommendations regarding data protection were followed.

\section{Conflict of Interest}

None declared

\section{REFERENCES}

1. Lavanchy D. Hepatitis B virus epidemiology, disease burden, treatment, and current and emerging prevention and control measures. J Viral Hepat. 2004 Mar;11(2):97-107.

2. Lok AS, McMahon BJ. Chronic hepatitis B. Hepatology. 2007 Feb;45(2):507-39. Erratum in: Hepatology. 2007 Jun;45(6):1347.

3. Wang Z, Zhang J, Yang H, Li X, Wen S, Guo Y, et al. Quantitative analysis of HBV DNA level and HBeAg titer in hepatitis B surface antigen positive mothers and their babies: $\mathrm{HBeAg}$ passage through the placenta and the rate of decay in babies. J Med Virol. 2003 Nov;71(3):360-6.

4. Jonas MM. Hepatitis B and pregnancy: an underestimated issue. Liver Int. 2009 Jan;29 Suppl 1:133-9.

5. Lin $\mathrm{HH}, \mathrm{Wu} \mathrm{WY}$, Kao JH, Chen DS. Hepatitis B post-partum e antigen clearance in hepatitis B carrier mothers: correlation with viral characteristics. J Gastroenterol Hepatol. 2006 Mar;21(3):605-9.

6. Söderström A, Norkrans G, Lindh M. Hepatitis B virus DNA during pregnancy and post partum: aspects on vertical transmission. Scand J Infect Dis. 2003;35(11-12):814- 9 .

7. FitzSimons D, Van Damme P. Prevention and control of hepatitis B in central and eastern Europe and the Newly Independent States, Siofok, Hungary, 6-9 October 1996. Vaccine. 1997 Oct;15(15):1595-7.

8. Sinha S, Kumar M. Pregnancy and chronic hepatitis B virus infection. Hepatol Res. 2010 Jan;40(1):31-48.

9. World Health Organization. Introduction of hepatitis B vaccine into childhood immunization services: management guidelines, including information for health workers and parents. Geneva: WHO; 2001.

10. Filadelfiova J, Gerbery D, Skobla D. Report on the living conditions of Roma in Slovakia. Bratislava: United Nations Development Programme Regional Bureau for Europe; 2007.

11. Kolarcik P, Madarasova Geckova A, Orosova O, van Dijk JP, Reijneveld SA. To what extent does socioeconomic status explain differences in health between Roma and non-Roma adolescents in Slovakia. Soc Sci Med. 2009 Apr;68(7):1279-84.

12. Elefsiniotis IS, Glynou I, Magaziotou I, Pantazis KD, Fotos NV, Brokalaki $\mathrm{H}$, et al. $\mathrm{HBeAg}$ negative serological status and low viral replication levels characterize chronic hepatitis B virus-infected women at reproductive age in Greece: a one-year prospective single center study. World J Gastroenterol. 2005 Aug 21;11(31):4879-82. 
13. Gyarmathy VA, Ujhelyi E, Neaigus A. HIV and selected blood-borne and sexually transmitted infections in a predominantly Roma (Gypsy) neighbourhood in Budapest, Hungary: a rapid assessment. Cent Eur J Public Health. 2008 Sep;16(3):124-7.

14. Cruz M, Dieguez A, Fos E, Hierro F. Epidemiologic survey in hepatitis B in Gypsy women. Eur J Epidemiol. 1988 Sep;4(3):314-7.

15. Menéndez MT, Cordero M, Viejo G, Miguel D, Malo de Molina A, Otero C. The serum markers in the pregnant population of the basic health area of El Natahoyo (Gijón). Aten Primaria. 1996 Jun 15;18(1):17-21. (In Spanish.)
16. Sangfelt P, Von Sydow M, Uhnoo I, Weiland O, Lindh G, Fischler B, et al. Serum ALT levels as a surrogate marker for serum HBV DNA levels in HBeAg-negative pregnant women. Scand J Infect Dis. 2004;36(3):182-5. 17. Xunrong L, Yan AW, Liang R, Lau GK. Hepatitis B virus (HBV) reactivation after cytotoxic or immunosuppressive therapy - pathogenesis and management. Rev Med Virol. 2001 Sept-Oct;11(5):287-99.

Received May 31, 2012 Accepted in revised form November 28, 2012 